\title{
Patterns of heart failure patients - Data from a single East-European centre
}

\author{
Robert Adrian DUMBRAVA ${ }^{1}$, Maria Andrada JIGA ${ }^{1}$, Dragos Gabriel IANCU ${ }^{1}$, \\ Liviu CRISTESCU ${ }^{1}$, Radu TATAR ${ }^{2}$, Andreea VARGA ${ }^{1,3}$ \\ ${ }^{1}$ Internal Medicine - Cardiology II Clinic, Emergency County Hospital, Targu Mures, Romania \\ ${ }^{2}$ The Doctoral School of "G.E. Palade" University of Medicine, Pharmacy, Sciences and Technology, \\ Targu Mures, Romania \\ ${ }^{3}$ Department ME2, Faculty of Medicine in English, "G.E. Palade" University of Medicine, Pharmacy, \\ Science and Technology, Targu Mures, Romania
}

\begin{abstract}
Objectives. The present study aims to describe the clinical and biological profile of heart failure patients from central Romania.

Material and method. A single centre-based retrospective, observational, descriptive study involving heart failure patients admitted from January 2018 to March 2020 was conducted. Only patients who had echocardiographic data determined by the same examiner were included. Patients were classified according to LVEF at admission in three subgroups: preserved LVEF subgroup (HFpEF, LVEF $\geq 50 \%$ ), moderate LVEF subgroup (HFmrEF, LVEF 40-49\%), reduced LVEF subgroup (HFrEF, LVEF < 40\%) and their clinical and biological profile was assessed. Comorbidities were recorded using the Charlson comorbidity index $(C C I)$.

Outcomes. A total of 175 patients (57.7\% males) were included in our study, with a mean age of $65.3 \pm$ 11.7 years. $44 \%$ of patients had more than one hospital admission during the studied timeframe. Mean calculated left ventricular ejection fraction was $47.1 \% \pm 12.1 \%$. According to LVEF $62.8 \%$ of patients were in HFpEF group, $20.5 \%$ in the HFrEF group and 16.5\% in the HFmrEF group. Dyspnoea was the most common presenting symptom in $65.7 \%$ of patients, being accompanied by fatigue in majority of cases (63.4\%). Charlson comorbidity index mean value for the study population was $4.6 \pm 2.1,4.6 \pm 2$ in the HFpEF group, $5.2 \pm 1.9$ in the HFmrEF group and $4.03 \pm 2.2$ in the HFrEF group. Arterial hypertension was the most frequent comorbid condition and risk factor at the same time, in both men and women.

Conclusions. The clinical and biological profile of the heart failure patients is complex, diverse and further research is needed for improving therapeutic and follow-up management of these patients.
\end{abstract}

Keywords: heart failure, clinical profile, Charlson comorbidity index

\section{INTRODUCTION}

Heart failure (HF) is a debilitating clinical syndrome characterized by typical symptoms and signs caused by a structural and/or functional cardiac abnormality, resulting in a reduced cardiac output and/or elevated intra-cardiac pressures at rest or during stress (1). In developed countries, the prevalence of $\mathrm{HF}$ is approximately $1-2 \%$ of the adult population, rising to $\geq 10 \%$ among people $>70$ years of age (2-5). HF high mortality rates are comparable to those of various malignancies, the 5-year mortality reaching almost $50 \%(1,6,7)$. 
Due to it's complexity, HF is a major burden for public health, being the main cause for hospitalization, re-hospitalization and outpatient visits (8). Heart failure patients often experience a considerable number of comorbid conditions, which further affect the disease management and prognostic (9). Ischemic heart disease, hypertension (HT), diabetes, dyslipidaemia and smoking also represent risk factors for developing HF. It is estimated that approximately 7-8 years after an acute coronary syndrome, one third of patients will eventually develop heart failure (10). The lifetime risk for developing heart failure increases in the presence of a history of myocardial infarction in both men and women (11). Hypertension associated risk of $\mathrm{HF}$ is smaller comparative to that associated with myocardial infarction. However, HT has a greater prevalence, therefore contributes more to the burden caused by $\mathrm{HF}$ (2). The presence of diabetes and insulin resistance is of major importance in HF development; diabetes itself increases the risk nearly as much as the presence of three other atherosclerotic risk factors (12). Cardiovascular disease risk factors, including dyslipidaemia in the form of increased ratio of total cholesterol to HDL cholesterol (13), smoking and obesity commonly precede the onset of heart failure, regardless of left ventricular ejection fraction (LVEF) (14).

To date, many studies have assessed the characteristics of heart failure in patients from different regions (15-17). Our study aims to describe a regional, clinical and biological profile of heart failure patients.

\section{MATERIAL AND METHODS}

A single centre-based, retrospective, observational, descriptive, non-interventional study involving 175 heart failure patients admitted to Targu Mures Emergency County Hospital, Internal Medicine Clinic II, Cardiology Department, from January 2018 to March 2020 was conducted. The inclusion criteria consisted in new-onset or worsening $\mathrm{HF}$ diagnosis according to European Society of Cardiology (ESC) 2016 Guidelines for the diagnosis and treatment of acute and chronic heart failure, age $>18$ years, irrespectively of comorbidities, and informed consent of the patients. To minimalize inter-observer variability (18), we only included patients who had echocardiographic data determined by the same examiner. The exclusion criterion was represented by lack of informed consent.

Patient's data were collected from electronic and paper-based recordings and the following variables were analysed: age, gender, environment, risk factors, type of admission, length of hospitalization, medical history, body mass index (BMI), NYHA classification, presenting symptoms, blood pressure and heart rate, electrocardiogram and transthoracic echocardiogra- phy measurements. Laboratory data included complete blood count, renal tests, serum iron, fasting blood sugar, serum uric acid, serum electrolytes, lipid profile and natriuretic peptides (NT-proBNP). Comorbidities were recorded using the Charlson comorbidity index (CCl), the most widely used index for 10-year survival prediction, validated in both clinical and surgical patients (19). The equation used for the calculation of 10 -year survival rate was: 10 -year survival $=0.983^{\wedge}$ $\left[\mathrm{e}^{\wedge}(\mathrm{CCl} \times 0.9)\right], \mathrm{e}=$ Euler's constant.

Furthermore patients were subclassified according to LVEF at admission in three subgroups: preserved LVEF subgroup (HFpEF, LVEF $\geq 50 \%$ ), moderate LVEF subgroup (HFmrEF, LVEF 40-49\%), reduced LVEF subgroup (HFrEF, LVEF < 40\%) and analysed their clinical and biological profile.

Transthoracic cardiac ultrasound was performed using a Philips Vivid E9 System (GE Vingmed Ultrasound AS, Norway) and the left ventricle ejection fraction (LVEF) was determined for each patient. For the electrocardiographic assessment, a BTL-08 Plus System (BTL Industries, Hertfordshire, Great Britain) was used. Laboratory investigations were performed with automatic systems Sysmex XS-1000i (Sysmex Europe $\mathrm{GmbH}$, Norderstedt, Germany) and Konelab Prime 60i (Thero Fisher Scientific, Waltham, SUA). For the assessment of renal function, estimated glomerular filtration rate was calculated using CKD-EPI Creatinine 2009 equation.

Statistical analysis was performed using Microsoft ${ }^{\circledR}$ Excel $^{\circledR} 2018$ (Microsoft Corporation, Redmond, WA, USA) and GraphPad Software (GraphPad Prism version 8.00 for Windows 64-bit, GraphPad Software, La Jolla California, USA). Categorical data are presented as frequencies (percentages) and continuous data are presented as the mean values \pm standard deviation (SD). Our work fulfils the international regulations stated in the Declaration of Helsinki and was approved by the Local Ethics Committee.

\section{RESULTS}

Our studied group included 175 patients $\mathbf{5 7 . 7 \%}$ males) diagnosed with heart failure according to 2016 ESC Guidelines, with a mean age of $65.3 \pm 11.7$ years. The male/female ratio was 1:1 in HFpEF group, 2.6:1 in HFmrEF and 2.2:1 in HFrEF group. 44\% of patients had more than one hospital admission during the studied timeframe, with an average hospitalization length of $7.2 \pm 3.3$ days. At admission, $62.8 \%$ of patients presented NYHA I or II clinical symptoms, $32.6 \%$ NYHA III and $4.6 \%$ manifested a more severe exacerbation of the disease with NYHA IV symptoms. Mean systolic and diastolic blood pressure at admission were $128.1 \pm 18.9$ $\mathrm{mmHg}$ and $78.1 \pm 10.9 \mathrm{mmHg}$ respectively. Dyspnoea 
was the most common presenting symptom in $65.7 \%$ of patients, being accompanied by fatigue in majority of cases (63.4\%). $33.1 \%$ of patients complained of chest pain, $28.5 \%$ of palpitations and $13.7 \%$ of lower limbs oedema. Symptoms like cough (8\%), oscillating blood pressure values (11.4\%), dizziness (5.7\%), headache $(5.1 \%)$, claudication $(4.5 \%)$, unintentional weight loss (4\%) and syncope (1.7\%) were also present but did not represent main causes for admission.

The common risk factors involved in heart failure development were identified in our study population, with the highest prevalence represented by HT (76.5\% of patients having a medical history of HT at admission), followed by chronic coronary syndrome (49.1\%), atrial fibrillation (46.2\%), obesity $(40.5 \%)$, dyslipidaemia (42.8\%) and diabetes mellitus (22.8\%).

After reviewing patient's medical history, the Charlson comorbidity index $(\mathrm{CCl})$ was calculated for each patient and the mean value for the study population was $4.6 \pm 2.1$. According to the LVEF, CCl means were $4.6 \pm 2$ in the HFpEF group, $5.2 \pm 1.9$ in the HFmrEF group and $4.03 \pm 2.2$ in the HFrEF group. Comorbid conditions of heart failure patients included in our study are presented in Table 1.

Transthoracic echocardiography was performed at admission or in the first 48 hours for the majority of patients; mean calculated LVEF was $47.1 \% \pm 12.1 \%$. $62.8 \%$ of patients were documented as having HFpEF, 20.5\% HFrEF and $16.5 \%$ HFmEF. In the reduced LVEF group, $6 \%$ presented NYHA IV symptoms, while $78.1 \%$ of patients were included in NYHA I or II class and had a preserved LVEF. Valvular heart disease $(62.3 \%$ males and $68.9 \%$ females) and chronic kidney disease $(60.3 \%$ males and $81 \%$ females) are the next most frequent comorbidities. Demographic, baseline clinical and biological characteristics of HF patients according to their LVEF are presented in Table 2 and Table 3.

\section{DISCUSSIONS}

The present study includes 175 patients diagnosed with heart failure admitted to our County's Hospital Cardiology ward. To date, there are numerous studies describing heart failure patterns including a similar number of patients. For example, a recent study from Sokolska et al. including 137 patients describes onset dyspnea patterns in acute HF patients (20). Similar to it, Nowak et al. describe acute HF phenotypes in the emergency department analyzing 127 patients (21). The mean ages of the patients included in the aforementioned studies $(65 \pm 13$ and $70 \pm 15.5$ years, respectively) are comparable to ours ( $65.3 \pm 11.7$ years),

TABLE 1. Comorbid conditions of the studied population. CVA or TIA - cerebrovascular accident or transient ischemic attack. COPD - chronic obstructive pulmonary disease. DCM - dilated cardiomyopathy. $\mathrm{N}$ - number of patients, $\%$ - percentage

\begin{tabular}{|l|c|c|c|}
\hline \multicolumn{1}{|c|}{ Comorbidities } & $\begin{array}{c}\text { Overall } \\
\text { (N = 175), (N, \%) }\end{array}$ & $\begin{array}{c}\text { Male } \\
(\mathbf{N}=\mathbf{1 0 1}),(\mathrm{N}, \%)\end{array}$ & $\begin{array}{c}\text { Female } \\
\text { (N = 74), (N, \%) }\end{array}$ \\
\hline Arterial hypertension & $134(76.5 \%)$ & $73(72.2 \%)$ & $61(82.4 \%)$ \\
\hline Chronic kidney disease & $121(69.1 \%)$ & $61(60.3 \%)$ & $60(81 \%)$ \\
\hline Valvular heart disease & $114(65.1 \%)$ & $63(62.3 \%)$ & $51(68.9 \%)$ \\
\hline Pulmonary hypertension & $94(53.7 \%)$ & $51(50.4 \%)$ & $43(58.1 \%)$ \\
\hline Chronic coronary syndrome & $86(49.1 \%)$ & $49(49.4 \%)$ & $37(50 \%)$ \\
\hline Atrial fibrillation & $81(46.2 \%)$ & $40(39.6 \%)$ & $41(55.4 \%)$ \\
\hline Obesity & $71(40.5 \%)$ & $34(33.66 \%)$ & $37(50.0 \%)$ \\
\hline Hypercholesterolemia & $50(28.5 \%)$ & $23(22.7 \%)$ & $27(36.4 \%)$ \\
\hline Myocardial infarction & $44(25.1 \%)$ & $33(32.6 \%)$ & $11(14.8 \%)$ \\
\hline Anaemia & $42(24.0 \%)$ & $20(19.8 \%)$ & $22(29.7 \%)$ \\
\hline Hyperuricemia & $41(23.4 \%)$ & $17(16.8 \%)$ & $24(32.4 \%)$ \\
\hline Diabetes mellitus & $40(22.8 \%)$ & $23(22.7 \%)$ & $17(22.9 \%)$ \\
\hline Hypertriglyceridemia & $25(14.2 \%)$ & $15(14.8 \%)$ & $10(13.5 \%)$ \\
\hline DCM & $24(13.7 \%)$ & $17(16.8 \%)$ & $7(9.4 \%)$ \\
\hline CVA or TIA & $20(11.4 \%)$ & $13(12.8 \%)$ & $7(9.4 \%)$ \\
\hline Peripheral vascular disease & $16(9.1 \%)$ & $15(14.8 \%)$ & $1(1.3 \%)$ \\
\hline Thyroid dysfunction & $16(9.1 \%)$ & $3(2.9 \%)$ & $13(17.5 \%)$ \\
\hline COPD & $16(9.1 \%)$ & $11(10.8 \%)$ & $5(6.7 \%)$ \\
\hline Localized solid tumour & $6(3.4 \%)$ & $4(3.9 \%)$ & $2(2.7 \%)$ \\
\hline Metastatic solid tumour & $5(2.8 \%)$ & $2(1.9 \%)$ & $3(4.0 \%)$ \\
\hline Liver disease & $5(2.8 \%)$ & $3(2.9 \%)$ & $2(2.7 \%)$ \\
\hline Peptic ulcer disease & $2(1.1 \%)$ & $1(0.9 \%)$ & $1(1.3 \%)$ \\
\hline Dementia & $2(1.1 \%)$ & $1(0.9 \%)$ & $1(1.3 \%)$ \\
\hline
\end{tabular}


TABLE 2. Demographic and baseline clinical characteristics of HF patients according to their LVEF. HFpEF - heart failure with preserved ejection fraction, $\mathrm{HFmEF}$ - heart failure with moderate ejection fraction, HFrEF - heart failure with reduced ejection fraction, $B M I$ - body mass index, SBP - systolic blood pressure, DBP - diastolic blood pressure, SD - standard deviation, $N$ - number of patients

\begin{tabular}{|c|c|c|c|c|}
\hline Characteristic & Overall $(\mathrm{N}=175)$ & HFpEF (N = 110) & HFmEF ( $N=29)$ & HFrEF ( $N=36)$ \\
\hline $\begin{array}{l}\text { Age, years } \\
(\text { mean } \pm \text { SD) (min-max) }\end{array}$ & $\begin{array}{c}65.3 \pm 11.7 \\
(31-90)\end{array}$ & $\begin{array}{c}66.3 \pm 11.1 \\
(31-89)\end{array}$ & $\begin{array}{c}67.5 \pm 10.6 \\
(47-90)\end{array}$ & $\begin{array}{c}60.4 \pm 13.0 \\
(34-83)\end{array}$ \\
\hline $\begin{array}{l}\text { Gender }(\mathrm{N}, \%) \\
\text { Male } \\
\text { Female }\end{array}$ & $\begin{array}{c}101(57.7 \%) \\
74(42.3 \%)\end{array}$ & $\begin{array}{l}55(50.0 \%) \\
55(50.0 \%)\end{array}$ & $\begin{array}{l}21(72.4 \%) \\
8(27.5 \%)\end{array}$ & $\begin{array}{l}25(69.4 \%) \\
11(30.5 \%)\end{array}$ \\
\hline Urban setting $(\mathrm{N}, \%)$ & $85(48.5 \%)$ & $52(47.2 \%)$ & $17(58.6 \%)$ & $16(44.4 \%)$ \\
\hline $\begin{array}{l}\text { BMI }\left(\mathrm{kg} / \mathrm{m}^{2}\right) \\
\text { mean } \pm \text { SD) (min-max) }\end{array}$ & $\begin{array}{l}29.2 \pm 5.4 \\
(17.4-51.5)\end{array}$ & $\begin{array}{c}29.3 \pm 5.0 \\
(17.4-45.1)\end{array}$ & $\begin{array}{c}29.6 \pm 5.9 \\
(20.4-51.5)\end{array}$ & $\begin{array}{c}28.5 \pm 6.2 \\
(19.8-48.0)\end{array}$ \\
\hline $\begin{array}{l}\text { NYHA functional class, (N, \%) } \\
\text { SII } \\
\text { III } \\
\text { IV }\end{array}$ & $\begin{array}{c}110(62.8 \%) \\
57(32.6 \%) \\
8(4.6 \%)\end{array}$ & $\begin{array}{c}86(78.1 \%) \\
23(20.9 \%) \\
1(0.9 \%) \\
\end{array}$ & $\begin{array}{c}12(41.3 \%) \\
16(55.1 \%) \\
1(3.4 \%) \\
\end{array}$ & $\begin{array}{c}12(33.3 \%) \\
18(50 \%) \\
6(16.6 \%) \\
\end{array}$ \\
\hline SBP $(\mathrm{mmHg}),($ mean $\pm \mathrm{SD})(\min -\max )$ & $\begin{array}{c}128.1 \pm 18.9 \\
(80-210)\end{array}$ & $\begin{array}{l}131 \pm 18 \\
(80-210)\end{array}$ & $\begin{array}{l}125 \pm 15 \\
(95-160)\end{array}$ & $\begin{array}{l}121 \pm 20 \\
(80-160)\end{array}$ \\
\hline $\mathrm{DBP}(\mathrm{mmHg}),($ mean $\pm \mathrm{SD})(\min -\mathrm{max})$ & $\begin{array}{c}78.1 \pm 10.9 \\
(50-110)\end{array}$ & $\begin{array}{c}79.2 \pm 9.9 \\
(50-110)\end{array}$ & $\begin{array}{c}77.4 \pm 11.4 \\
(55-100)\end{array}$ & $\begin{array}{c}75.1 \pm 11.1 \\
(55-100)\end{array}$ \\
\hline $\begin{array}{l}\text { Heart rate (beats/min) } \\
(\text { mean } \pm S D)(\text { min-max) }\end{array}$ & $\begin{array}{c}75.2 \pm 18.1 \\
(40-188)\end{array}$ & $\begin{array}{c}73.3 \pm 15.7 \\
(48-120)\end{array}$ & $\begin{array}{c}74.5 \pm 18.1 \\
(40-114)\end{array}$ & $\begin{array}{c}81.8 \pm 23.4 \\
(54-188)\end{array}$ \\
\hline $\begin{array}{l}\text { Risk factors (N, \%) } \\
\text { Diabetes mellitus } \\
\text { Arterial hypertension } \\
\text { Obesity } \\
\text { Hypercholesterolemia } \\
\text { Hypertriglyceridemia }\end{array}$ & $\begin{array}{c}40(22.8 \%) \\
134(76.5 \%) \\
71(40.5 \%) \\
50(28.5 \%) \\
25(14.2 \%) \\
\end{array}$ & $\begin{array}{l}25(22.7 \%) \\
96(87.2 \%) \\
46(41.8 \%) \\
36(32.7 \%) \\
14(12.7 \%)\end{array}$ & $\begin{array}{c}8(27.5 \%) \\
22(75.8 \%) \\
12(41.3 \%) \\
7(24.1 \%) \\
5(17.2 \%) \\
\end{array}$ & $\begin{array}{c}7(19.4 \%) \\
16(44.4 \%) \\
12(33.3 \%) \\
7(19.4 \%) \\
6(16.6 \%) \\
\end{array}$ \\
\hline Deaths (N, \%) & $1(0.5 \%)$ & $1(1.1 \%)$ & $0(0 \%)$ & $0(0 \%)$ \\
\hline
\end{tabular}

TABLE 3. Baseline biological characteristics of HF patients according to their LVEF. HFpEF - heart failure with preserved ejection fraction, HFmEF - heart failure with moderate ejection fraction, HFrEF - heart failure with reduced ejection fraction, NT-proBNP $N$-terminal pro-brain natriuretic peptide, eGFR - estimated glomerular filtration rate, $N$-number of patients

\begin{tabular}{|c|c|c|c|c|}
\hline $\begin{array}{l}\text { Laboratory findings } \\
\text { (units, range) }\end{array}$ & $\begin{array}{c}\text { Overall } \\
(\mathrm{N}=175)\end{array}$ & $\begin{array}{c}\text { HFpEF } \\
(\mathrm{N}=110)\end{array}$ & $\begin{array}{l}\text { HFmEF } \\
(\mathrm{N}=29)\end{array}$ & $\begin{array}{l}\text { HFrEF } \\
(\mathrm{N}=36)\end{array}$ \\
\hline NT-proBNP $(\mathrm{pg} / \mathrm{ml},<125 \mathrm{pg} / \mathrm{ml})$ & $\begin{array}{c}2252 \pm 2968.8 \\
(58-13959) \\
\end{array}$ & $\begin{array}{c}1612 \pm 2923.6 \\
(58-12614) \\
\end{array}$ & $\begin{array}{c}1654 \pm 181.1 \\
(71-6371) \\
\end{array}$ & $\begin{array}{c}2314 \pm 3441.0 \\
(197-13959) \\
\end{array}$ \\
\hline Creatinine (mg/dl, 0.7-1.2 mg/dl) & $\begin{array}{l}1.1 \pm 0.7 \\
(0.5-8.0) \\
\end{array}$ & $\begin{array}{l}1.0 \pm 1.1 \\
(0.5-4.4) \\
\end{array}$ & $\begin{array}{l}1.6 \pm 1.5 \\
(0.6-8.0) \\
\end{array}$ & $\begin{array}{l}1.1 \pm 0.4 \\
(0.7-2.9) \\
\end{array}$ \\
\hline $\begin{array}{l}\text { eGFR }\left(\mathrm{ml} / \mathrm{min} / 1.73 \mathrm{~m}^{2},\right. \\
\left.>90 \mathrm{ml} / \mathrm{min} / 1.73 \mathrm{~m}^{2}\right)\end{array}$ & $\begin{array}{l}71.9 \pm 26.0 \\
(5.4-128.9)\end{array}$ & $\begin{array}{c}73.6 \pm 24.6 \\
(13.8-124.2) \\
\end{array}$ & $\begin{array}{l}62.9 \pm 31.0 \\
(5.4-127.1)\end{array}$ & $\begin{array}{c}74.8 \pm 24.6 \\
(22.4-129.9) \\
\end{array}$ \\
\hline Hemoglobin (g/dl, 13-17 g/dl) & $\begin{array}{l}13.5 \pm 1.8 \\
(5.5-17.8) \\
\end{array}$ & $\begin{array}{c}13.6 \pm 2.82 \\
(5.5-17) \\
\end{array}$ & $\begin{array}{c}13.0 \pm 2.2 \\
(6.2-17) \\
\end{array}$ & $\begin{array}{l}13.5 \pm 1.9 \\
(8.1-17.8) \\
\end{array}$ \\
\hline Platelets $(\times 103 / \mu \mathrm{l}, 150-400 \times 103 / \mu \mathrm{l}$ & $\begin{array}{l}231.0 \pm 67.4 \\
(51.0-486.0) \\
\end{array}$ & $\begin{array}{l}235.3 \pm 62.6 \\
(51.0-433.0) \\
\end{array}$ & $\begin{array}{l}219.8 \pm 82.3 \\
(84.0-486.0) \\
\end{array}$ & $\begin{array}{l}227.3 \pm 69.6 \\
(95.0-388.0) \\
\end{array}$ \\
\hline Serum iron $(\mu \mathrm{mol} / \mathrm{l}, 9.0-30.4 \mu \mathrm{mol} / \mathrm{l})$ & $\begin{array}{l}15.1 \pm 7.6 \\
(3.3-54.8) \\
\end{array}$ & $\begin{array}{l}14.0 \pm 5.9 \\
(3.3-44.4) \\
\end{array}$ & $\begin{array}{c}16.2 \pm 10.0 \\
(3.8-54.8) \\
\end{array}$ & $\begin{array}{l}17.6 \pm 9.5 \\
(4.9-45.3) \\
\end{array}$ \\
\hline Blood glucose (mg/dl, 70-105 mg/dl) & $\begin{array}{c}110 \pm 29.2 \\
(61.7-329.7) \\
\end{array}$ & $\begin{array}{l}109.7 \pm 29.3 \\
(79.3-329.7) \\
\end{array}$ & $\begin{array}{c}109 \pm 21.6 \\
(82.6-163.3) \\
\end{array}$ & $\begin{array}{l}111.5 \pm 34.2 \\
(61.7-244.4) \\
\end{array}$ \\
\hline Urea (mg/dl, 15-46 mg/dl) & $\begin{array}{c}60.8 \pm 65.4 \\
(13.2-570.5)\end{array}$ & $\begin{array}{c}53.7 \pm 55.8 \\
(13.2-532.1) \\
\end{array}$ & $\begin{array}{c}55.2 \pm 24.5 \\
(23.0-108.1) \\
\end{array}$ & $\begin{array}{c}83.8 \pm 98.5 \\
(21.3-570.5) \\
\end{array}$ \\
\hline Uric acid $(\mu \mathrm{mol} / \mathrm{l}, 200-400 \mu \mathrm{mol} / \mathrm{l})$ & $\begin{array}{c}326.9 \pm 112.1 \\
(83-885)\end{array}$ & $\begin{array}{c}308.0 \pm 109.4 \\
(83-837) \\
\end{array}$ & $\begin{array}{c}352.5 \pm 90.8 \\
(188-563) \\
\end{array}$ & $\begin{array}{c}366.2 \pm 124.4 \\
(206-885) \\
\end{array}$ \\
\hline Sodium (mmol/l, 136-145 mmol/l) & $\begin{array}{l}141 \pm 4.0 \\
(125-150)\end{array}$ & $\begin{array}{l}141.6 \pm 3.6 \\
(127-150)\end{array}$ & $\begin{array}{c}140 \pm 3.8 \\
(130-150) \\
\end{array}$ & $\begin{array}{c}139.4 \pm 4.8 \\
(125-147)\end{array}$ \\
\hline Potassium (mmol/l, 3.5-5.1 mmol/l) & $\begin{array}{l}4.3 \pm 0.5 \\
(2.9-5.8) \\
\end{array}$ & $\begin{array}{l}4.2 \pm 0.4 \\
(2.9-5.7) \\
\end{array}$ & $\begin{array}{l}4.6 \pm 0.4 \\
(3.8-5.5) \\
\end{array}$ & $\begin{array}{l}4.3 \pm 0.5 \\
(3.4-5.8) \\
\end{array}$ \\
\hline Total cholesterol (mg/dl, 110-200 mg/dl) & $\begin{array}{l}172.5 \pm 47.7 \\
(63.4-322.1) \\
\end{array}$ & $\begin{array}{l}180.6 \pm 18.9 \\
(79.6-322.1) \\
\end{array}$ & $\begin{array}{l}158.5 \pm 46.6 \\
(81.2-292.7) \\
\end{array}$ & $\begin{array}{l}159.3 \pm 49.7 \\
(63.4-292.3) \\
\end{array}$ \\
\hline Triglycerides (mg/dl, 50-170 mg/dl) & $\begin{array}{l}126.2 \pm 59.0 \\
(25.6-364.0)\end{array}$ & $\begin{array}{l}124.4 \pm 56.2 \\
(25.6-278.1)\end{array}$ & $\begin{array}{l}118.8 \pm 56.3 \\
(33.6-273.6)\end{array}$ & $\begin{array}{l}137.3 \pm 68.6 \\
(51.3-364.0)\end{array}$ \\
\hline
\end{tabular}


with a male predominance $(80 \%$ and $52 \%$, respectively) which is also found in our study (57.7\%). $62.8 \%$ of patients presented mild clinical symptoms at admission, classified as NYHA I or II. This could be due to the fact that only $12.5 \%$ of the patients were first addressed to the Emergency Department. Although $76.5 \%$ of patients had a history of hypertension, mean systolic and diastolic blood pressures at admission where relatively normal range, maybe reflecting a good adherence to antihypertensive medication of this category of patients. Numerous studies described dyspnea as the major complaint of HF patients $(20,22)$. Our results are in line with these findings, $65.7 \%$ of our patients presenting dyspnea as the main cause for hospital admission. Almost as common, fatigue was present in $63.4 \%$ of patients, followed by chest pain, palpitations and lower limbs edema. In a study by Farmakis et al. (22) along with dyspnea (73.4\%), 43.8\% of patients presented fatigue, $42.7 \%$ presented peripheral edema and $27.9 \%$ reported weight gain. Opposite to this finding, in our study $4 \%$ of patients reported unintentional weight loss. These results support the involvement of different mechanisms of the disease either in weight gain through water retention, or weight loss in advanced heart failure.

In heart failure patients, a plethora of comorbid conditions may be identified. Our results show that hypertension is the most frequent comorbid condition and risk factor at the same time, in both men and women. A history of myocardial infarction was identified in $32.6 \%$ of males and $14.8 \%$ of female patients (25.1\% of the entire studied population). Nowak et al. (21) reported hypertension as the most frequent comorbidity in their patients (79\%) and diabetes mellitus second most frequent (52\%). A history of myocardial infarction was identified in $34 \%$ of patients, while CKD was present in only $43 \%$ of patients compared to our study (69.1\%). Diabetes mellitus was identified in less than $23 \%$ of patients, similar to the above-mentioned study by Sokolska et al (20).

The $\mathrm{CCl}$ mean value in our patients was $4.6 \pm 2.1$. Interestingly, in the HFrEF subgroup the mean $\mathrm{CCl}$ was $4.03 \pm 2.2$, while in the HFpEF group the mean was 4.6 \pm 2 . Thus, the HFrEF group may have a better 10 -year survival rate $(52.4 \%)$ than the HFpEF group (34.0\%). This could owe to the fact that HF patients with a reduced ejection fraction benefit from better implemented therapy strategies and follow-up that the oth- er categories. Although controversial, similar results were obtained by other studies as well (23).

When we indexed patients according to their LVEF, 62.8\% were in HFpEF group, $20.5 \%$ in the HFrEF group and $16.5 \%$ in the HFmrEF group. A different percentage was reported in a study (22) comprising 3,257 patients of whom $22.9 \%$ had a LVEF $\geq 50 \%$, 24.9\% had a LVEF between $40-49 \%$ and in $52.1 \%$ of patients the LVEF had values < 40\%. Mean systolic and diastolic blood pressures tend to decrease with the LVEF (131 \pm 18 and $79.2 \pm 9.9 ; 125 \pm 15$ and $77.4 \pm 11.4 ; 121 \pm 20$ and $75.1 \pm 11.1$ ), while heart rate values increase (73.3 $\pm 15.7 ; 74.5 \pm 18.1$ and $81.8 \pm 23.8$ ). A study by Gök et al. (24) found comparative results: in patients aged 6579 years mean SBP was $103 \pm 36 \mathrm{mmHg}$ in HFrEF group, $114 \pm 22 \mathrm{mmHg}$ in HFmrEF group and $120 \pm 14$ $\mathrm{mmHg}$ in the HFpEF group. In elderly patients (aged > 80 years) accordingly to EF values, SBP values were 92 $\pm 48 \mathrm{mmHg}, 115 \pm 23$ and $113 \pm 19$ respectively. The mean heart rate values were directly proportional with the mean SBP and LVEF in both age groups (69 \pm $24,76 \pm 12$ and $79 \pm 13$ in patients aged $65-79$ years; $64 \pm 31,77 \pm 16$ and $78 \pm 16$ in patients $>80$ years).

\section{Study limitations}

Registered data were based only on the diagnostic coding of the hospital and patient's medical history, which depended on the accuracy and integrity of the documentation. Another issue is related to a relative small number of cases admitted in a single centre, thus more data should be added in order to obtain a more precise pattern of heart failure patients.

\section{CONCLUSIONS}

Heart failure patients express multifaceted clinical and biological profiles pointed in various HF trials. The observed discrepancies could be due to trial-specific issues, country differences, patient characteristics, outcomes and treatment effect heterogeneity. Further research into characterizing HF patients is mandatory for improving therapeutic and follow-up management of these patients.

\section{Acknowledgement}

Robert Adrian Dumbrava and Maria Jiga have equal contributions to this paper.

Conflict of interest: none declared Financial support: none declared 


\section{REFERENCES}

1. Díez-Villanueva P, Alfonso F. Heart failure in the elderly. J Geriatr Cardiol. 2016; 13(2):115-117.

2. Mosterd A, Hoes AW. Clinical epidemiology of heart failure. Heart. 2007;93:1137-46.

3. Redfield MM, Jacobsen SJ, Burnett JC et al. Burden of systolic and diastolic ventricular dysfunction in the community: appreciating the scope of the heart failure epidemic. JAMA. 2003;289:194-202.

4. Bleumink GS, Knetsch AM, Sturkenboom MCJM et al. Quantifying the heart failure epidemic: Prevalence, incidence rate, lifetime risk and prognosis of heart failure The Rotterdam Study. Eur Heart J England. 2004;25:1614-1619.

5. Ceia F, Fonseca C, Mota T et al. Prevalence of chronic heart failure in Southwestern Europe: the EPICA study. Eur $\mathrm{J}$ Heart Fail. 2002;4:531-539.

6. Danielsen R, Thorgeirsson G, Einarsson $\mathrm{H}$ et al. Prevalence of heart failure in the elderly and future projections: the AGES-Reykjavík study. Scand Cardiovasc J. 2017;51(4):183-189.

7. Askoxylakis V, Thieke C, Pleger ST et al. Long-term survival of cancer patients compared to heart failure and stroke: $A$ systematic review. BMC Cancer. 2010;10:105

8. Bui A, Horwich T, Fonarow G. Epidemiology and risk profile of heart failure. Nat Rev Cardiol. 2011;8:30-41.

9. Moe G. Heart failure with multiple comorbidities. Curr Opin Cardiol. 2016;31(2):209-216.
10. Hellermann JP, Goraya TY, Jacobsen SJ et al. Incidence of heart failure after myocardial infarction: is it changing overtime? Am J Epidemiol. 2003;157:1101-1107.

11. Lloyd-Jones DM, Larson MG, Leip EP et al. Lifetime risk for developing congestive heart failure: the Framingham Heart Study. Circulation. 2002;106:3068-3072.

12. Bibbins-Domingo K, Lin F, Vittinghoff $E$ et al. Predictors of heart failure among women with coronary disease. Circulation. 2004;110:1424-1430.

13. From AM, Leibson CL, Bursi $F$ et al. Diabetes in heart failure: prevalence and impact on outcome in the population. Am J Med. 2006;119:591-599.

14. Lee DS, Gona P, Vasan RS et al. Relation of disease pathogenesis and risk factors to heart failure with preserved or reduced ejection fraction: insights from the Framingham Heart Study of the National Heart, Lung, and Blood Institute. Circulation. 2009;119:3070-3077.

15. Tomasoni D, Adamo M, Lombardi CM, Metra M. Highlights in heart failure. ESC Heart Fail. 2019;6(6):1105-1127.

16. Lam CSP. Heart failure in Southeast Asia: facts and numbers. ESC Heart Fail. 2015;2:46-49.

17. Nagai T, Sundaram V, Shoaib A et al. Validation of U.S. mortality prediction models for hospitalized heart failure in the United Kingdom and Japan. Eur J Heart Fail. 2018;20:1179-1190.

18. Mercuri M, Gafni A. Examining the role of the physician as a source of variation: Are physician-related variations necessarily unwarranted? J Eval Clin Pract. 2018;24(1):145-151.

19. Yurkovich M, Avina-Zubieta JA, Thomas J et al. A systematic review identifies valid comorbidity indices derived from administrative health data. $J$ Clin Epidemiol. 2015;68(1):3-14

20. Sokolska JM, Sokolski M, Zymliński R et al. Patterns of dyspnoea onset in patients with acute heart failure: clinical and prognostic implications. ESC Heart Fail. 2019; 6(1):16-26.

21. Nowak RM, Reed BP, DiSomma $S$ et al. Presenting phenotypes of acute heart failure patients in the ED: Identification and implications. Am J Emerg Med. 2016;35(4):536-542.

22. Farmakis $D$, Simitsis $P$, Bistola $V$ et al. Acute heart failure with mid-range left ventricular ejection fraction: clinical profile, in-hospital management, and short-term outcome. Clin Res Cardiol. 2017; 106(5):359-368.

23. Tribouilloy $C$, Rusinaru $D$, Mahjoub $\mathrm{H}$ et al. Prognosis of heart failure with preserved ejection fraction: A 5 year prospective population-based study. Eur Heart J. 2008; 29(3):339-347.

24. Gök G, Kılıç S, Yaşar Sinan Ü et al. Epidemiology and clinical characteristics of hospitalized elderly patients for heart failure with reduced, mid-range and preserved ejection fraction. Heart Lung. 2020; 49(5):495-500. 